\title{
ISU PENGGUNAAN FROG VLE DALAM PEMBELAJARAN SAINS
}

Titik Rahayu ${ }^{1}$, Syafrimen Syafril2 ${ }^{2}$, Mohamed Yusoff bin Mohd Nor ${ }^{1}$, Agus Pahrudin ${ }^{2}$

${ }^{1}$ Fakulty of Education, Universiti Kebangsaan Malaysia, 43600 UKM Bangi, Selangor, Malaysia

${ }^{2}$ Universitas Islam Negeri Raden Intan Lampung, Jl. Letkol H. Endro Suratmin, Sukarame, Bandar Lampung, Indonesia

\begin{abstract}
Frog Virtual Learning Environment (Frog VLE) merupakan salah satu aplikasi pendukung pembelajaran memanfaatkan Information and Communication Technology (ICT) dalam pembelajaran sains pada abad ke-21. Konsep paper ini cuba melihat berbagai isu dalam penggunaan Frog VLE bagi menjalankan aktiviti pembelajaran sains. Beberapa kajian terdahulu dianalisis secara mendalam untuk tujuan tersebut. Hasil analisis menunjukkan bahawa Frog VLE belum banyak digunakan untuk mendukung pembelajaran sains oleh guru. Justeru Frog VLE perlu diberi tumpuan serius demi menambahbaik proses pembelajaran sains pada masa hadapan, guru mesti diberi latihan secara berterusan dan konsisten dalam penggunaan Frog VLE tersebut dalam proses pembelajaran sains.
\end{abstract}

Kata Kunci: Penggunaan FROG VLE, Aktiviti pembelajaran sains, Latihan berteruan

\section{A. PENGENALAN}

Guru merupakan fasilitator pemandu yang sangat berperanan dalam mewujudkan tujuan pembelajaran di sekolah (Rasul, Ismail, Ismail, Rajuddin, \& Rauf, 2009). Untuk memenuhi keperluan tersebut guru perlu mewujudkan pembelajaran dalam persekitaran kelas (Oluwatumbi, 2015). Salah satu cabaran pembelajaran saat ini adalah berkaitan dengan efektiviti, kualiti dan kesesuaian pelbagai sumber sokongan teknologi maklumat dalam pembelajaran (Malaysia, 2013). Untuk mendepani cabaran tersebut guru perlu mengemaskini pengetahuan, kompetensi secara berterusan supaya sentiasa update dengan keperluan pembelajaran semasa dan yang akan datang.

Proses pendidikan saat ini berada pada zon digital dan berbeza dengan tuntutan sebelumnya, iaitu pemanfaatan teknologi sebagai penyokong pembelajaran satu keniscayaan (Iberahim, Mahamod, \& Mohamad, 2017). Justeru, keperluan ini merupakan penyesuaian yang 
urgen bagi guru (Uche, Chineze, Kaegon \& Chiemezie, Okata, 2016). Beliau mencadangkan beberapa kemahiran yang perlu dimiliki oleh guru saat ini adalah pemikiran kritis dan penyelesaian masalah, komunikasi, kolaborasi, kreativiti dan inovasi, maklumat, kemahiran media dan teknologi, inisiatif dan hala tuju diri, kemahiran kebudayaan, produktiviti dan akauntabiliti, kepimpinan dan tanggungjawab. Kemahiran dalam menggunakan teknologi untuk berhubung dengan pelajar merupakan salah satu kemahiran yang tidak dapat dielakan (Ibrahim et al., 2017). Untuk itu, guru memerlukan panduan untuk menggunakan teknologi agar dapat digunakan secara selamat dan berkesan (Boholano, 2017).

Penggunaan teknologi di negara yang sedang membangun merupakan fenomena yang baru (Adegbenro, Gumbo, \& Olakanmi, 2017). Di Eropah kemahiran itu disebut dengan ekemahiran yang berkaitan dengan kecekapan, keupayaan untuk membangun, dan menggunakan teknologi dalam konteks persekitaran pengetahuan (Mitrovic et al., 2012). Kepentingan tekniologi untuk kemajuan berbagai aktiviti masyarakat sivil dan perniagaan (Mitrovic et al. (2012). Untuk itu, guru perlu mahir dalam menggunakan teknologi untuk menciptakan proses pembelajaran yang berkesan. Adegbenro et al. (2015) menyatakan bahawa fungsi proses, kandungan, pengetahuan pedagogi yang berkesan dapat dilakukan menggunakan teknologi.

Kajian sebelumnya menunjukkan bahwa penggunaan teknologi dalam pembelajaran dipengaruhi oleh sikap guru dalam penggunaan teknologi tersebut (Chigona dan Chigona 2010). Saincheza et al (2012) mendapati bahawa sikap guru sangat positif terhadap penggunaan teknologi dalam pembelajaran, walaupun masih terdapat berbagai cabaran pengintegrasian teknologi berkenaan dalam pembelajaran di sekolah. Cabaran dimaksudkan adalah (i) sokongan pimpinan, pelaburan yang tidak konsisten, infrastruktur dan sumber, keperluan pembangunan profesional tambahan dan sokongan serta penubuhan teknologi dalam penilaian dan kurikulum (Rabah, 2015). Pengintegrasian teknologi dalam pengajaran dapat memberikan pengajaran yang pelbagai, membolehkan pelajar lebih autonomi, lebih banyak pembelajaran kooperatif, manakala maklumat dan sumber berkaitan dengan keperluan dan kepentingan pelajar, semuanya dapat membantu mendapatkan tahap penglibatan pelajar terhadap penggunaan teknologi dalam pembelajaran (Rabah, 2015).

Kementerian Pendidikan Malaysia (KPM) telah memperkenalkan sistem e-pembelajaran melalui persekitaran pembelajaran maya (VLE) hampir pada sepuluh ribu buah sekolah rendah
Comment [Office2]: Rujukan ini masih manual Yu

Comment [Office3]: Masih manual Comment [Office4]: Masih manual

Comment [Office5]: Masih manual 
dan menengah (Ali, 2015). Inisiatif KPM menggalakkan penggunaan teknologi adalah untuk mewujudkan suasana pembelajaran yang lebih efisyen kepada guru, ibu bapa, dan murid (Noraini, 2010). Frog VLE merupakan satu sistem berasaskan web yang menyerupai dunia pendidikan sebenar, dengan mengintegrasikan pendidikan konvensional dalam persekitaran maya. Dalam web Frog VLE, guru boleh memuat naik lagu, video, gambar, latihan dalam Microsoft word, power point, forum dan chatroom untuk berinteraksi (Ashikin, Ibrahim, \& Osman, 2013; Zurina Hamid \& Sanitah Mohd Yusof, 2014).

Panduan dalam membangunkan media pengajaran berasaskan multimedia yang mampu memberikan impak maksimum dalam proses pembelajaran (Rafiza \& Maryam 2013). Guru-guru perlu menggunakan Frog VLE ini secara maksimum berdasarkan satu garis panduan berteraskan aspek pedagogi dan teori yang bersesuaian dalam penggunaan aplikasi tersebut (Kasim \& Tasir, 2014). Selain itu, Frog VLE dalam pembelajaran mempunyai kesan positif, iaitu (i) kesan positif ke atas pencapaian pelajar dari segi keberkesanan sebagai seorang pelajar, meningkatkan kualiti pembelajaran dan sebagai alat bantu dalam kursus, (ii) pembelajaran berdikari, (iii) meningkatkan motivasi pelajar untuk belajar dari segi maklumbalas ke atas aktiviti pelajar dan mengalakkan komunikasi dan pembelajaran kolaboratif melalui forum, chat dan e-mail untuk perbincangan (Barker dan Gossman, 2013).

Pengintegrasian teknologi dalam proses pembelajaran membawa kesan positif kepada pencapaian pelajar (Abdulahi, Nor Hidayati, 2012; Songkram (2015), mampu meningkatkan pencapaian matlamat pembelajaran (Mohd Azli \& Abdul Latif, 2012). Manakala proses pembelajaran menggunakan platform Frog VLE merupakan satu pendekatan untuk menangani keperluan kepelbagaian gaya pembelajaran dalam menghasilkan impak positif kepada kemahiran pelajar (Mohd Azli, Wong, \& Goh, 2016). Kelebihan pendekatan pembelajaran ini masih gagal menarik perhatian guru untuk menggunakan Frog VLE sebagai platform utama pembelajaran di sekolah (Mahizer \& Mohd Azli, 2016). Kertas konsep ini coba mengkaji isu, cabaran, dan implikasinya penggunaan Frog VLE dalam menjalankan aktiviti pembelajaran.
Comment [Office6]: Masih manual

Comment [Office7]: Masih manual

Comment [Office8]: Masih manual

Comment [Office9]: Masih manual.

Comment [Office10]: Masih manual

Comment [Office11]: Masih manual. 


\section{B. ISU DAN CABARAN PENGGUNAAN FROG VLE DALAM PEMBELAJARAN SAINS}

Untuk menghadapi cabaran pendidikan 2013-2025 telah digariskan anjakan ke-7 pemanfaatkan teknologi bagi meningkatkan kualiti pembelajaran di Malaysia (Noraini et al., 2015), salah satunya adalah penggunaan Frog VLE dalam pembelajaran. Diantara cabaran dalam penggunaan Frog VLE adalah berkaitan dengan integrasi teknologi dengan pembelajaran (Adegbenro, et al 2015, Flanagan dan Shoffner, 2011), dan kekurangan latihan bagi guru-guru dalam perkhidmatan (Adegbenro, Gumbo, dan Olakanmi, 2017). Dari pelbagai cabaran tersebut, sekolah perlu menggalakkan guru memiliki kemahiran dalam penggunaan teknologi di sekolah.

Penggunaan ICT di sekolah belum mencapai tahap yang memberangsangkan, sama ada dari segi kualiti mahupun kuantiti (Kasim \& Tasir, 2014). Guru kurang menggunakan Frog VLE kerana kurang pengetahuan dan tidak cukup masa untuk membuat persediaan pembelajaran melalui Frog VLE (Shahfiezul Shahaimi \& Fariza Khalid, 2015). Ummu Salma dan Fariza (2014) menyatakan bahawa 2\% sahaja guru menggunakan Frog VLE dalam pembelajaran. Majoriti guru hanya menggunakan VLE sebagai repositori untuk pelajar mendapatkan bahan pembelajaran seperti Power Point dan senarai bacaan (Rienties et al, 2016). Kesedaran guru dalam bekerja pada abad ke-21, dan kurangnya galakkan pihak sekolah kepada guru terhadap penggunaan teknologi dalam pengajaran di persekitaran kelas juga menjadi isu (Uche et al, 2016).

Penyelidik lain juga mendapati bahawa penggunaan teknologi di sekolah terhad, dalam beberapa kes hampir tidak wujud sama sekali (Hew Syed, 2016). Dari segi fasiliti sekolah didapati bahawa faktor utama guru kurang menggunakan teknologi untuk proses pembelajaran adalah terkait dengan bilangan komputer (Yusof Boon \& Sani, 2011). Kebanyakan sekolah di luar Bandar mendapat masalah terkait dengan capaian internet, jaringan, sokongan teknikal, kurang latihan yang berkesan, masa yang terhad dan kekurangan kecekapan guru, sehingga penggunaan Frog VLE belum tercapai sepenuhnya (Ghavifekr et al, 2016; Nurazilawati, 2013). Ibu bapa seharusnya lebih berfikiran terbuka untuk menyediakan kemudahan internet, pemilikan komputer di rumah untuk meningkatkan pencapaian pelajar dalam bidang teknologi (Hazura et. al 2012; Maisarah, 2012). Bagaimanapun, isu dalam pemenuhan keperluan murid tersebut sangat berkait rapat dengan pendapatan ibu bapa. 
Isu yang terjadi di luar Malaysia lebih kurang sama dengan isu Malaysia, iaitu terkait dengan kelemahan penggunaan ICT disebabkan kerana guru terhad dalam pengetahuan, pangkalan data, alat persidangan video, dan alat pengurusan pembelajaran seperti blackboard dalam amalan pengajaran mereka (Adegbenro et al, 2017). Selain itu pada kajian Adegbenro et al (2015) dan Flanagan \& Shoffner (2011) bahawa secara umum guru bermasalah dengan keyakinan diri menggunakan ICT dalam PdP, guru yakin dengan kemahiran asas mereka tetapi kurang yakin dalam menangani beberapa aplikasi teknikal. Hal tersebut terjadi kerana beberapa faktor, iaitu (i) kebolehaksesan dan sambungan rangkaian yang terhad, (ii) sekolah dengan sokongan teknikal terhad, (iii) kekurangan latihan yang efektif, (iv) masa terhad, dan (v) kurang kecekapan guru (Ghavifekr et al, 2016). Guru-guru di kawasan bandar berpendapat penggunaan ICT dan akses ICT lebih tinggi daripada guru-guru di kawasan luar bandar. Kajian Haji \& Park (2017) mendapati bahawa tidak terdapat perbezaan yang signifikan dalam penggunaan ICT awam, swasta, akses kepada ICT, kecekapan dan sokongan latihan.

Dari beberapa kajian di atas dapat dirumuskan bahawa terdapat pelbagai faktor dalaman mahupun luaran yang menjadi penghalang mengintegrasikan ICT dalam bentuk Frog VLE di sekolah. Beberapa faktor yang menghalang guru untuk mengintegrasikan ICT di sekolah ialah keyakinan atau kompetensi terhadap ICT, akses kepada ICT, latihan guru, masa, dan masalah teknikal atau sokongan (Adegbenro et al 2015; 2017, Flanagan \& Shoffner 2011). Selain itu pengetua sekolah juga sangat berperanan. Noraini et al, (2015) mendapati bahawa masih terdapat lompang dan jurang dalam integrasi teknologi di sekolah, kerana kurangnya kemahiran pengetua dalam mengurus teknologi dan sumber manusia di sekolah.

\section{CADANGAN DAN IMPLIKASI}

Pembelajaran Frog VLE di sekolah bukan sahaja menyokong aktiviti e-pembelajaran seperti menyampaikan maklumat, menguruskan bahan kursus, dan menjalankan penilaian. Pembelajaran Frog VLE dapat menyediakan persekitaran media yang kaya dengan pelbagai grafik, video, animasi, dan bunyi (Berns, Gonzalez-Pardo, Camacho, 2013). Disokong oleh Georgouli, Skalkidis, \& Guerreiro (2008) dalam Cheok, Wong, \& Fauzi (2017) pembelajaran Frog VLE dapat meningkatkan minat guru dan murid, serta meningkatkan keberkesanan pengajaran, menjimatkan kos, dan meningkatkan cara pembelajaran tradisional. Menurut Thah (2014) 
melalui pembelajaran Frog VLE guru boleh menetapkan pelajaran, ujian dan markah. Manakala pelajar boleh mengemukakan kerja rumah, melihat nota dan dokumen penting terkait dengan pembelajaran. Selain itu, pentadbir sekolah boleh mengatur kalendar mereka dan menyebarkan notis melalui Frog VLE.

Dari pelbagai isu yang telah dipaparkan, beberapa cadangan yang dapat dikongsikan bagi menambahbaik pengajaran dalam Frog VLE, adalah (i) guru perlu dilatih penggunaan ICT dengan baik agar terbiasa dan menambah kemahiran mengaplikasikan ICT (Adegbenro, Gumbo, \& Olakanmi, 2017). Saincheza et al (2012) menyatakan bahawa untuk kejayaan pelaksanaan program intervensi, kecekapan guru perlu dipertimbangkan dengan teliti dalam reka bentuk dan pelaksanaan program latihan integrasi ICT. Perlu dilakukan usaha berterusan untuk menangani berbagai isu seperti dipaparkan sebelum ini. Guru dibenarkan membentuk kumpulan pembangunan diri dengan melibatkan rakan-rakan yang lebih kompeten dalam teknologi, selain itu perlu diadakan program pembangunan profesional, serta digalakkan menggunakan strategi pengajaran dan pembelajaran berasaskan ICT (Uche et al, 2016).

Pentadbir sekolah perlu jelas matlamat pelaksanaan pembelajaran maya, pelan pelaksanaan melibatkan semua warga sekolah dan ibu bapa perlu dibangunkan. Program peningkatan kemahiran perlu diatur untuk memastikan guru yang berminat dan berkemahiran sahaja yang aktif dalam pelaksanaan, pemantauan perlu dijalankan, maklumbalas berhubung pelaksanaan patut dikumpulkan dan dinilai bagi tujuan penambahbaikan, menilai semula pelan berdasarkan maklumbalas dan memperbaiki strategi pelaksanaan (Ghavifekr, Afshari, M \& Amla, 2012). Capaian internet perlu ditambah, bebanan kerja guru dikurangkan dan guru perlu merobah minda, membuat perancangan pengajaran lebih awal dan bersedia mengikuti kursus yang dianjurkan berkaitan dengan aplikasi Frog VLE (Abdullah et al., n.d.).

Menurut Cheok, Wong, \& Ahmad Fauzi Ayub (2017) langkah-langkah yang boleh digunakan untuk mengekalkan dan meningkatkan pembelajaran berbasis digital adalah mengetahui keadaan yang sedang dihadapi guru. Dengan demikian sekolah perlu memberikan cara yang tepat bagi meningkatkan profesionalisma guru dalam bidang teknologi. Selain itu guru mendapatkan manfaat untuk meningkatkan pelaksanaan pembelajaran di kelas (Cheok et al, 2017). Frog VLE sangat penting bagi institusi pendidikan kerana berdampak kepada kualiti pembelajaran. Pengajaran Frog VLE hingga kini cenderung memberi penekanan lebih kepada ciri-ciri, 
komponen dan aspek teknikal daripada cara mengoptimumkan penggunaan Frog VLE di dalam bilik darjah (Sa'adon, Dahlan, \& Zainal (2013). Guru berada di barisan hadapan, oleh itu latihan dan sokongan untuk guru merupakan komponen penting dalam pendidikan e-pembelajaran. Justeru latihan secara berterusan perlu dilakukan (Kaur \& Hussein, 2015).

\section{KESIMPULAN}

Penguasaan dan penggunaan ICT merupakan simbol era saat ini. Salah satu yang terkandung dalam ICT adalah system berasaskan web Frog VLE (Virtual Learning Environment), yang sangat memudahkan proses pembelajaran. Tidak dinafikan bahawa teknologi menjadi suplement utama dalam dunia Pendidikan hari ini. Justeru, proses pembelajaran berjalan lebih mudah dan berkesan dengan penggunaan IT. Untuk itu, perlu diberikan perhatian khusus untuk peningkatan kemahiran guru dalam menghadapi berbagai cabaran semasa, dan menjadikan proses pendidikan menjadi lebih bermakna.

\section{RUJUKAN}

Abdulahi, NorHidayati, Z., and E. 2012. An evaluation of virtual learning environment readiness in higher education institutions (HEIs). Journal of Information Systems Research and Innovation, 2, 86-94.

Abdullah, N., Noh, N. M., Azmah, N., Yusuff, N., Mansor, R., Pendidikan, U., \& Idris, S. (n.d.). Aplikasi Persekitaran Pengajaran Maya ( Frog VLE ), 3(2), 63-76.

Adegbenro, B.J., Gumbo, M.T. \& Olugbara, O.O. 2015. Exploring technological knowledge of Office Data Processing teachers: Using factor analytic methodology. In M.L. Niess \& H. Gillow-Wiles (eds.), Handbook of research on teacher education in the digital age. Available at: www.igi- global.com/book/handbook-research-teacher-educationdigital/123127 (accessed 27 October 2015).

Adegbenro, J. B., Gumbo, P. M. T., \& Olakanmi, E. E. 2017. In-Service Secondary School Teachers' Technology Integration Needs in an ICT- Enhanced Classroom, 16(3), 79-87.

Albirini, A. 2006. Teachers' attitudes toward information and communication technologies: The case of Syrian EFL teachers. Computers \& Education, 47(4), 373-398.

Ali, I. H. B. M. 2015. Persekitaran Pembelajaran Maya (VLE FROG) : Penilaian Kendiri Guru Matematik Sekolah Rendah, 1-24. 
Ashikin, N., Ibrahim, B., \& Osman, K. 2013. Kesan Frog VLE Secara Pembelajaran Kooperatif Terhadap Pencapaian, KBAT dan Minat Pelajar Bagi Subjek Kimia. Fakulti Pendidikan, Universiti Kebangsaan Malaysia, 635-649.

Barker, J., \& Gossman, P. 2013. The Learning Impact of a Virtual Learning Environment: Students' views. Teacher Advancement Network Journal, 5(2).

Berns, A., Gonzalez-Pardo, A., \& Camacho, D. 2013. Game-like language learning in 3-D virtual environments. Computers \& Education, 60(1), 210-220.

Boholano, H. 2017. Smart Social Networking: 21st Century Teaching And Learning Skills. Research in Pedagogy, 7(1), 21-29. https://doi.org/10.17810/2015.45.

Campbell, C., Al Harthi, A., \& Karimi, A. 2015. Teachers cloud-based content creation in light of the TPACK Framework: Implications for teacher education. In Australasian Society for Computers in Learning and Tertiary Education (ASCILITE), 399-403.

Cavanaugh,C, Gillan, K.J., Kromrey.J, Hess,H., Blomeyer,R. 2004.The effects of distance education on K-12 students outcomes: A meta- analysis. Naperville, IL: Learning Point associates. Retrieved from http://www.ncrel.org/tech/distance/K12distance.pdf.

Cheok, M. L., Wong, S. L., \& Ahmad Fauzi Ayub. 2017. Teachers' perceptions of e-learning in Malaysian Secondary Schools. Malaysian Online Journal of Educational Technology (MOJET), 5(2), 14.

Chigona, A. \& Chigona, W. 2010. An investigation of factors affecting the use of ICT for teaching in the Western Cape schools. ECIS 2010 Proceedings. Pretoria, South Africa.

Claro, M., Presis, D., Martin, E., Jara, I., Valenzuela, S. \& Nussbaum, M. 2012. Assessment of 21 st century ICT skills in Chile: Test design and results from high school level students. Computers \& Education, 59 (3),1042-1053.

Colorado, J. T., \& Eberle, J. 2010. Student demographic and success in online learning environments. Emporia State Research Studies, 40 (1), 4-10.

Flanagan, S. \& Shoffner, M. 2011. Two teachers' technology use: Recommendations for English teacher preparation: Research highlights in technology and teacher education. Society for Information \& Teacher Education. USA.

Ghavifekr, Afshari, M \& Amla, S. 2012. Management strategies for E- Learning system as the core component of systemic change: A qualitative analysis. Life Science Journal, 9(3), 2190- 2196

Ghavifekr, S., Kunjappan, T., Ramasamy, L., \& Anthony, A. 2016. Teaching and Learning with ICT Tools: Issues and Challenges from Teachers' Perceptions. Malaysian Online Journal 
of Educational Technology, 4(2), 38-57. Retrieved from http://bit.ly/2fRI88H.

Haji, S. A., \& Park, I. 2017. Teachers ' Use of Information and Communications Technology in Education : Cameroon Secondary Schools Perspectives, 16(3), 147-153.

Iberahim, A. R., Mahamod, Z., \& Mohamad, W. M. R. W. (2017). Pembelajaran Abad Ke-21 Dan Pengaruhnya Terhadap Sikap, Motivasi Dan Pencapaian Bahasa Melayu Pelajar Sekolah Menengah. Jurnal Pendidikan Bahasa Melayu -JPBM (Malay Language Education Journal-MyLEJ), 7(2), 77-88.

Jamaludin Mohaidin. 2000. Kesedaran dan Pembelajaran Maya, Konvensyen Pendidikan Universiti Teknologi Malaysia, Skudai, Johor.

Kasim, R. A., \& Tasir, Z. 2014. Strategi pembelajaran kolaboratif atas talian untuk penggunaan frog VLE. International Education Postgraduate Seminar 2014, (2003), 654-666.

Leese, M. 2009. Out of class - out of mind? The use of a virtual learning environment to encourage student engagement in out of class activities. British Journal of Educational Technology, 40(1), 70-77.

Mahizer, H., \& Mohd Azli, Y. 2016. Frog VLE (Virtual Learning Environment) in Teaching and Learning: Acceptance and Its Implementation. Journal of Research, Policy \& Practice of Teachers \& Teacher Education, 6(2), 67-77. Retrieved from http://ejournal.upsi.edu.my/article/2016AR001298.

Malaysia, K. P. (2013). Pelan Pembangunan Pendidikan Malaysia 2013-2025.

Mitrovic, Z., Sharinf, M., Taylor, W. \& Wesso, H. 2012. Systemic approach to e-skilling in South Africa. International Journal of Education and Development using Information and Communication Technology (IJEDICT), 9(3), 103-123.

Mohd Azli, Y., \& Abdul Latif, G. 2012. Kesan pendekatan pembelajaran berasaskan projek berteraskan teknologi terhadap pencapaian dan penerimaan pelajar. Jurnal Pendidikan Bitara UPSI, 5, 44-61. Retrieved from http://jpbu.upsi.edu.my/index.php/component/content/article/11-vol-5/6-mohd-azli- binyeop-dan-abdul-latif-haji-gapor.

Mohd Azli, Y., Wong, K., \& Goh, P. S. C. 2016. Blended learning: pedagogy, learning styles, and assessment activities in the classroom. International Journal of Advanced and Applied Sciences, 3(11), 36-39. Retrieved from http://doi.org/https://doi.org/10.21833/ijaas. 2016.11.007.

Mohd Azli, Y., Wong, K.T., \& N. M. 2016. Pembelajaran Teradun: Satu tinjauan literatur terhadap faktor-faktor penerimaan guru melalui model-model penerimaan. Journal of Research, Policy \& Practice of Teachers \& Teacher Education, 6(1), 67-85. 
Noraniah, Nor Haizan \& Razana. 2000. Memodelkan Modul Pengajaran Dalam Pendidikan Jarak Jauh, Konvensyen Pendidikan UTM 2000, Sekudai Johor.

Noraini, A., Hamidon, K., Mohd. Izham, M. H., Binti Abdullah, N., Bin Khalid, H., \& Mohd Izham Bin Mohd Hamzah, M. 2015. Amalan Kepimpinan Teknologi Pengetua dalam Pengintegrasian ICT di Sekolah Menengah. 3rd Global Summit on Education, 2015(March), 684-694.

Oluwatumbi, O. S. 2015. E- Classroom of the 21 st Century: Information Gaps. Journal of Education and Practice, 6(18), 67-72.

Pelgrum, E. \& Anderson, L. 2001. Appropriate use of ICT in facilitating teaching and learning. Available at: Edb. Gov.hk//EN/content.447.

Rabah, J. 2015. Benefits and Challenges of Information and Communication Technologies ( ICT) Integration in Québec English Schools, 14(2), 24-31.

Rafiza Abdul Razak \& Maryam Abdul Rahman. 2013. Pembinaan Media Pengajaran Berasaskan Multimedia Di Kalangan Guru ICTL. Jurnal Kurikulum \& Pengajaran Asia Pasifik. April 2013, Bil. 1 Isu 2: 20-31.

Rasul, M. S., Ismail, M. Y., Ismail, Rajuddin, R., \& Rauf, R. A. (2009). Aspek kemahiran 'employability' yang dikehendaki majikan industri pembuatan masa kini. Jurnal Pendidikan Malaysia, 34(2), 67-79.

Razak, R. A., \& Yusop, F. D. 2013. Designing framework of electronic continued professional development for teachers (e-CPD). In Annual International Conference on Management and Technology in Knowledge, Service, Tourism \& Hospitality.

Rienties, B., Giesbers, B., Lygo-Baker, S., Ma, H. W. S., \& Rees, R. 2016. Why some teachers easily learn to use a new virtual learning environment: a technology acceptance perspective. Interactive Learning Environments, 24(3), 539-552.

Ruthven, S., Hennessy, P. \& Bindley, T. 2004. Teacher representations of the successful use of computer-based tools and resources in secondary-school English, Mathematics and Science. Teaching and Teacher Education, 20259-275.

Sa'don, N. F. B., Dahlan, H. B. M., \& Zainal, H. B. 2013. Derivation for design of Virtual Learning Environment (VLE) framework for Malaysian schools. In Research and Innovation in Information Systems (ICRIIS), 2013 International Conference on (pp. 570575). IEEE.

Sancheza, A., Marcosb, J.M., Gonzaleza, M. \& GuanLina, H. 2012. In-service teachers' attitudes towards the use of ICT in the classroom. Procedia - Social and Behavioral Sciences, $46: 1358-1364$. 
Shahfiezul Shahaimi dan Fariza Khalid. 2015. Persekitaran Pembelajaran Maya Frog (VLEFROG) Di Sekolah-Sekolah Di Malaysia: Pelaksanaan Dan Cabaran. Prosiding Seminar Kebangsaan Pendidikan Negara Kali Ke-5, 2015.

Songkram, N. 2015. E-learning system in virtual learning environment to develop creative thinking for learners in higher education. Procedia - Social and Behavioral Sciences, 174, 674-679. https://doi.org/10.1016/j.sbspro.2015.01.600.

Thah, S. S. 2014. Leveraging Virtual Learning Environment to Scale Up Quality Teaching and Learning in Malaysia. Asia-Pacific Collaborative education Journal, 10(1), 1-17.

Uche, Chineze, Kaegon, L., \& Chiemezie, Okata, F. 2016. Teachers' Level of Awareness of 21st Century Occupational Roles in Rivers State Secondary Schools. Journal of Education and Training Studies, 4(8). https://doi.org/10.11114/jets.v4i8.1621.

Zurina Hamid, \& Sanitah Mohd Yusof. 2014. Pelaksanaan Pengajaran dan Pembelajaran Menggunakan Frog VLE Bagi Mata Pelajaran Bahasa Melayu di Sekolah Rendah. 1st International Education. Retrieved from http://eprints.utm.my/60880/1/SanitahMohdYusof2014_PelaksanaanPengajaranDanPemb elajaranMenggunakanFrogVLE.pdf. 